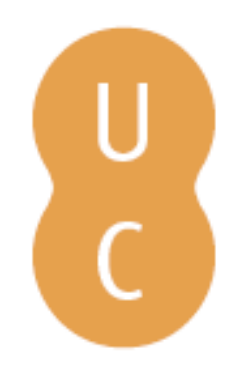

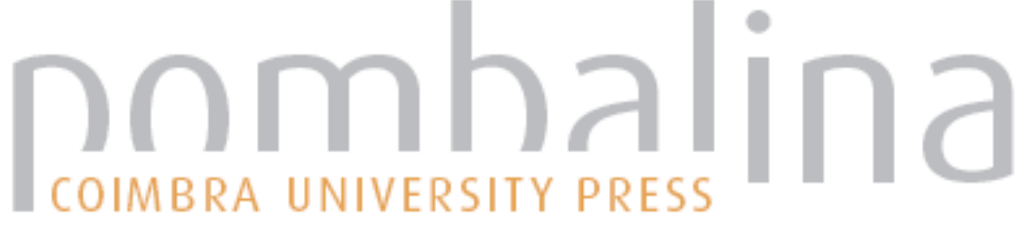

\section{Breves reflexões sobre a assimetria temporal em ciência}

Autor(es): $\quad$ Formosinho, Sebastião J.

Publicado por: Imprensa da Universidade de Coimbra; Gradiva

URL

persistente: URI:http://hdl.handle.net/10316.2/32689

DOI: $\quad$ DOI:http://dx.doi.org/10.14195/978-989-26-0389-6_15

Accessed : $\quad$ 26-Apr-2023 06:14:03

A navegação consulta e descarregamento dos títulos inseridos nas Bibliotecas Digitais UC Digitalis, UC Pombalina e UC Impactum, pressupõem a aceitação plena e sem reservas dos Termos e Condições de Uso destas Bibliotecas Digitais, disponíveis em https://digitalis.uc.pt/pt-pt/termos.

Conforme exposto nos referidos Termos e Condições de Uso, o descarregamento de títulos de acesso restrito requer uma licença válida de autorização devendo o utilizador aceder ao(s) documento(s) a partir de um endereço de IP da instituição detentora da supramencionada licença.

Ao utilizador é apenas permitido o descarregamento para uso pessoal, pelo que o emprego do(s) título(s) descarregado(s) para outro fim, designadamente comercial, carece de autorização do respetivo autor ou editor da obra.

Na medida em que todas as obras da UC Digitalis se encontram protegidas pelo Código do Direito de Autor e Direitos Conexos e demais legislação aplicável, toda a cópia, parcial ou total, deste documento, nos casos em que é legalmente admitida, deverá conter ou fazer-se acompanhar por este aviso.

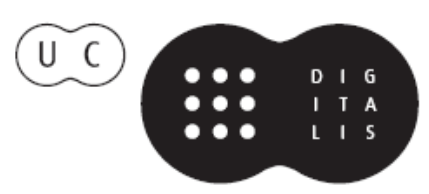


C I E N C I A I B E R T A

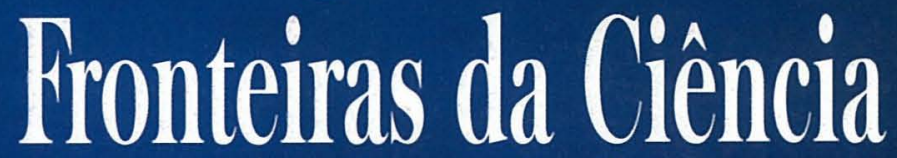

Desenvolvimentos Recentes - Desafios Futuros

RUI FAUSTO • CARLOS FIOLHAIS • JOÃO FILPE QUURRÓ

Coordenadores

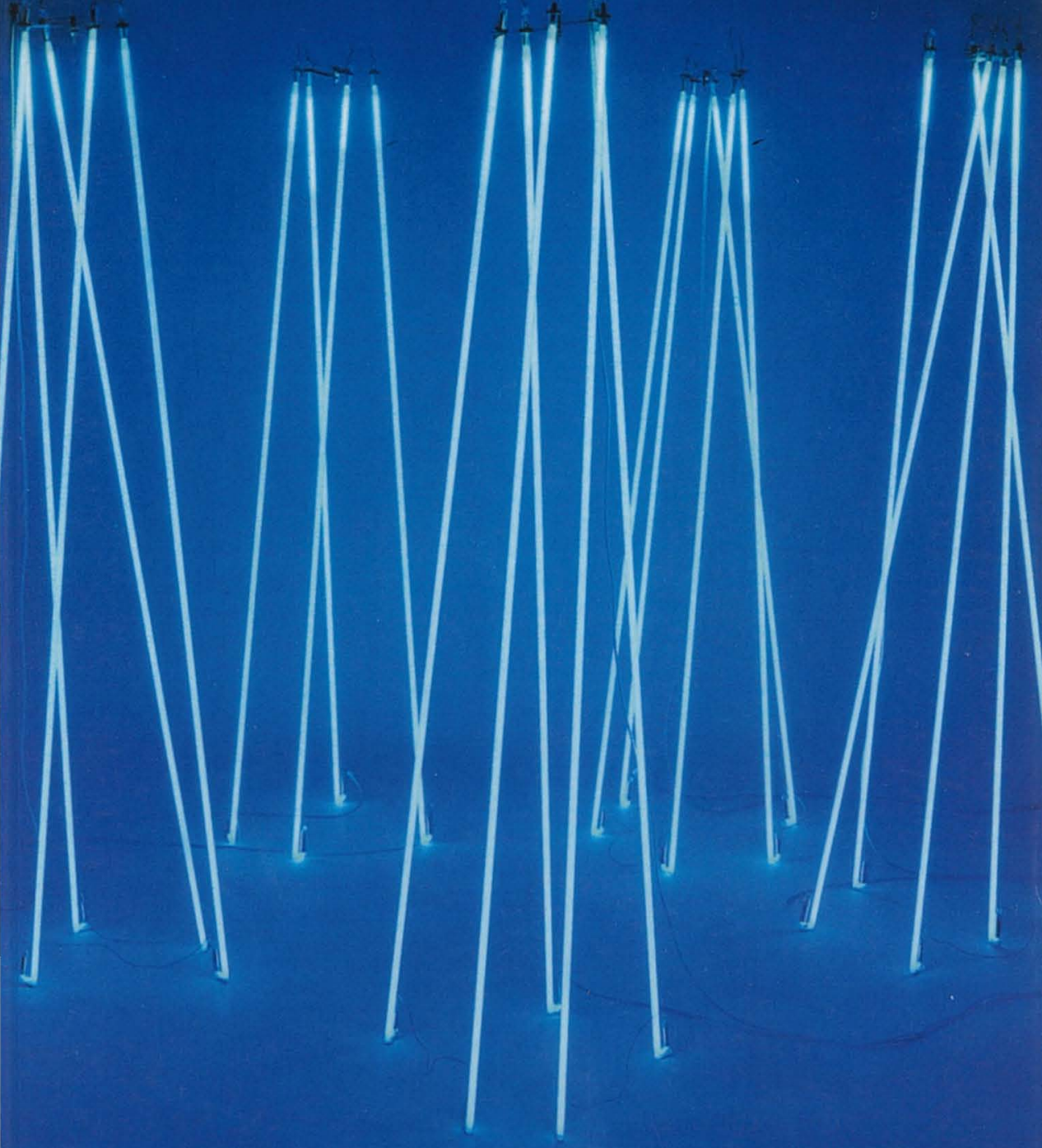

gradiva - Imprensa da Universidade de Coimbra 
(Página deixada propositadamente em branco) 


\section{RUI FAUSTO, CARLOS FIOLHAIS JOÃO FILIPE QUEIRÓ \\ Coordenadores}
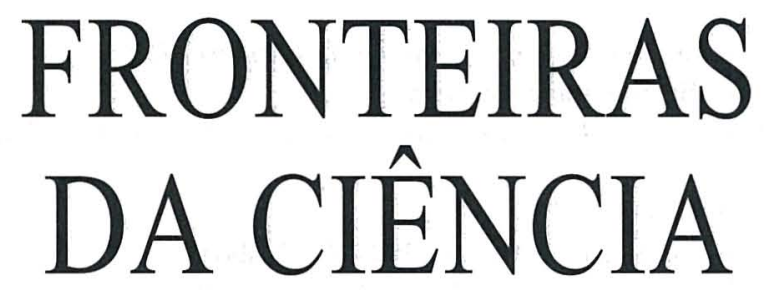

Desenvolvimentos Recentes Desafios Futuros 
(C) Gradiva - Publicações, L. da / Imprensa da Universidade de Coimbra, 2003 Coordenação editorial: Rui Fausto, Carlos Fiolhais e João Filipe Queiró Tradução: Jean Burrows, Vivien Burrows, Rui Fausto, Carlos Fiolhais e João Filipe Queiró

Revisão do texto: Isabel Pedrome

Capa: António Barros [Imprensa da Universidade. Coimbra], sobre imagem de «Águas Vivas», escultura de Silvestre Pestana, 2001

Foto: António Alves; Infografia: ESTÍMULUS [design]; Cortesia: Galeria Alvarez-Arte Contemporânea

Paginação: António Resende e Paula Isabel Jorge

Impressão e acabamento: G.C. - Gráfica de Coimbra, L. ${ }^{d a}$

Reservados os direitos para Portugal por:

Gradiva - Publicações, L. ${ }^{\text {da }}$ e Imprensa da Universidade de Coimbra

Gradiva - Publicações, L.da

Rua Almeida e Sousa, 21, r/c, esq.•1399-041 Lisboa

Telefs. $213974067 / 8 \cdot 213971357 \cdot 213953470$

Fax $213953471 \cdot$ Email: gradiva@ip.pt

URL: http://www.gradiva.pt

Imprensa da Universidade de Coimbra

Rua Antero de Quental, 195 • 3000-033 Coimbra

Telefs. 351239853110

Fax 3512398531 19・e-mail: fjrpress@ci.uc.pt

URL: http://www.imp.uc.pt

ISBN: 972-662-923-3

1." edição: Agosto de 2003

Depósito legal n. ${ }^{\circ} 199$ 463/2003 
Sebastião J. Formosinho

Departamento de Química

Faculdade de Ciências e Tecnologia

Universidade de Coimbra

\section{Breves reflexões sobre a assimetria temporal em ciência}

Nós somos criaturas no tempo e é a partir desta perspectiva temporal que adoptamos o nosso ponto de vista sobre o mundo e os seus fenómenos. Em relação ao tempo, praticamente nunca ascendemos a um ponto arquimediano de uma visita a partir de nenhures, como diria Thomas Nagel, ou, para ser mais preciso na linguagem, a uma perspectiva do não quando, como diria Huw Price.

A assimetria temporal do passado, presente e futuro - o fluxo de tempo - é uma característica objectiva do mundo físico que se nos impõe ou é um mero artifício, fruto do nosso modo subjectivo de visualizar esse mundo? Encontramos nesta atitude a perspectiva do antropocentrismo que atormenta cientistas e filósofos e que pode resultar da nossa própria constituição ou da circunstância de habitarmos uma dada região do universo de características excepcionais - atrito, gravidade, etc. - , que tomamos como normais e universais. O paradoxal é que o mundo físico seja, ou aparente ser, assimétrico, quando as leis físicas são simétricas em relação ao tempo. Os cosmólogos tendem sempre a explicar o estado presente do universo com base em estados passados e não em estados futuros. A este respeito, Frank Tipler é mais coerente com a simetria das leis físicas. Em The Physics of Immortality, procura compreender a globalidade do universo a partir de condições de fronteira no futuro e não no passado, porque é no futuro que se encontra a maior porção do espaço-tempo. 
Neste problema da assimetria temporal convém distinguir entre a assimetria do tempo e a assimetria das coisas no tempo. O próprio tempo pode ser assimétrico de vários modos; um, óbvio, é ter um começo, mas não um fim. Basicamente a conferência de Petrosky e Prigogine conduziu-nos com mestria pelo segundo destes caminhos.

Se, de facto, há um fluxo temporal, ele terá uma certa direcção e uma dada velocidade. A direcção será positiva no sentido do futuro ou ao contrário? Ou será isto somente uma questão de convenção? Porque, se não há nada que, objectivamente, forneça o sentido positivo do tempo, afirmar que a entropia cresce depende da nossa escolha do gráfico temporal. Se invertermos a escala no gráfico, o aumento de entropia converte-se num decréscimo de entropia. Há um gradiente unidireccional de entropia nos sistemas isolados, e todos os gradientes têm o mesmo tipo de inclinação. Sendo assim, como Price assevera, em Time's Arrow and Archimedes' Point, o sentido positivo do tempo deve estar objectivamente para além da assimetria termodinâmica.

A Segunda Lei da Termodinâmica não contém nenhuma assimetria na sua formulação estatística. Como o próprio Boltzmann reconhece, se, por exemplo, a entropia de uma dada amostra de um gás aumentar no sentido do futuro, pode aplicar-se o mesmo argumento estatístico no sentido do passado. A argumentação estatística contabiliza combinações possíveis, mas desconhece qualquer direcção temporal. A partir de um dado estado inicial, existem muito mais histórias possíveis que correspondem a macroestados de mais alta entropia do que a macroestados de baixa entropia. Por isso, do ponto de vista estatístico, a entropia também devia crescer no sentido do passado. Alguns filósofos consideram que, normalmente, estamos tão imbuídos da nossa perspectiva temporal que aplicamos uma dada argumentação selectivamente só num dado sentido temporal e não a revertemos. Claro que com este tipo de procedimento encontramos sempre uma assimetria temporal que provém do nosso próprio raciocínio. Como sugere Price na obra acima referida, um bom procedimento para avaliarmos se são as nossas próprias intuições que carreiam a perspectiva temporal é revertermos essa mesma perspectiva temporal. $\mathrm{O}$ facto de o resultado nos parecer estranho é uma boa indicação de que havia uma assimetria temporal no nosso próprio raciocínio.

No caso vertente, o que nos surpreende é que a entropia cresça numa direcção e não na outra. Por outras palavras, não causa surpresa a hipótese estatística de Boltzmann para a entropia; o que surpreende é que ela falhe tão rotundamente no sentido inverso.

São as coisas excepcionais que carecem de explicação. Se o equilíbrio termodinâmico é a condição natural da matéria, o que carece de ser 
explicado são os desvios dessa condição. No nosso exemplo do sistema gasoso, o que requer explicação é o sistema visto ao contrário no tempo, o gás a entrar na garrafa depois de se ter difundido na atmosfera porque este microestado é infrequente nesta perspectiva. Ou, no sentido normal do tempo, do passado para o futuro, o que carece de ser explicado em primeiro lugar é o modo como o gás entrou na garrafa.

É neste entendimento que Roger Penrose afirma que os estados de alta entropia são estados naturais, que não carecem de ser explicados. Portanto, o enigma assenta não no modo como o universo alcançou um estado de alta entropia, mas sim em como ele começou num estado de baixa entropia. O que havemos de reconhecer é que a Segunda Lei da Termodinâmica está associada a um estado inicial de muito baixa probabilidade, logo a seguir ao big bang. E mesmo Boltzmann invocou este tipo de raciocínio antrópico da baixa probabilidade inicial para contrapor à argumentação de Zermelo. Hoje, se nos basearmos nas estimativas de Roger Penrose, a probabilidade de um universo tão ordenado, homogéneo, isotrópico e macio (sem granularidades) junto à singularidade inicial - big bang - é, de facto, infinitamente baixa, 1 em $10^{10123}$ universos. Se revertermos a nossa perspectiva temporal, vendo o big bang como um colapso gravitacional, o que se prevê é que este universo inicial seja rugoso e irregular e não macio. Mais: como nos revela a teoria do caos, não haveria evolução nem sobrevivência numa região de equilíbrio termodinâmico. Mas parece que haveria processos muito mais prováveis para gerar o gradiente de entropia necessário ao desenvolvimento da vida. Como argumenta Penrose, o nosso universo é muito menos provável do que parece ser necessário para o aparecimento da vida inteligente.

Mas Petrosky e Prigogine trouxeram-nos agora uma outra perspectiva. A assimetria temporal não provém das leis físicas, mas dos sistemas. Há sistemas, como a Terra em volta do Sol, que parecem reversíveis, no sentido em que se víssemos o movimento ao contrário não o acharíamos estranho. Mas o mesmo não acontece com muitos outros sistemas; têm um sentido proibido. Por exemplo, um processo irreversível tão simples como uma reacção $A \rightarrow B$, formulado com base em cadeias de Markov, conduz à solução correcta a partir dos produtos quando se transforma $t \mathrm{em}-t$, mas encontram-se probabilidades de transição negativas e outras superiores à unidade. O resultado é esquisito, o que revela tal sentido proibido.

A sensibilidade dos sistemas caóticos acarreta horizontes limitados de previsibilidade. Eles são sistemas dinâmicos não integráveis, na acepção de Poincaré. Em princípio, esta sensibilidade devia aplicar-se quer a um dado conjunto de condições iniciais a partir do qual se caminha para o 
futuro, quer a condições finais a partir das quais se recua para o passado. Contudo, há uma assimetria de comportamento nos dois tipos de sistemas: a passagem da descrição dos sistemas não integráveis baseada em trajectórias para ensembles (conjunto de sistemas réplica) pode sempre fazer-se, mas o inverso deixa de ser verdade. Ora tal não sucede com os sistemas integráveis, onde a conversão é possível nos dois sentidos.

Esta visão traz-nos uma ciência cheia de novas oportunidades e previsões de fenómenos novos e mais consentânea com as nossas intuições, ou convicções, sobre o livre arbítrio. Ilya Prigogine sempre entendeu que o mundo não pode ser um filme policial que estamos a ver pela primeira vez, não sabendo quem é o criminoso, embora, na verdade, o criminoso já esteja determinado por quem realizou o filme.

Temos, quiçá, de admitir que a reversibilidade temporal das leis da física não é, de facto, compatível com a assimetria temporal da maioria dos sistemas naturais. Será que teremos de admitir uma bidimensionalidade para o tempo: o tempo reversível, o da física, e o tempo irreversível, o da química? Será que é no tempo da física que temos consciência da nossa permanente identidade no decurso das transformações por que passamos ao longo da nossa própria vida e para além dela? Mas não é apenas esta a nossa percepção desse tempo da sucessão reversível. Se tocarmos uma peça de música do fim para o princípio, será que deixa de ser música? 
(Página deixada propositadamente em branco) 
 \\ A palavra "fronteiras" pode ser tomada em} diferentes sentidos. Pode referir-se aos limites, necessariamente provisórios, entre o conhecido e o desconhecido, ou aos limites entre o possivel e o impossivel, e, dentro do possivel, entre o desejável e 0 indesejável. Fronteiras podem também ser as delimitações, nem sempre nítidas, entre ciência e não-ciência, e dentro da ciência, entre as várias disciplinas. Quais são então as fronteiras da ciência?

Neste livro, a resposta a esta pergunta é dada, segundo as mais diferentes perspectivas, por um conjunto notável de personalidades, cientistas ou não, entre as quais se contam três Prémios Nobel.

Rui Fausto, Carlos fiolhais e JoÃo Fillipe Queiró são, respectivamente, professores de Química, Física e Matemática na Faculdade de Ciências e Tecnologia da Universidade de Coimbra. 